\title{
Assessing the Factors Creating Unhealthy Life Style and High Risk Behaviour
}

\author{
Maira Aslam \\ Research Scholar, Department of Sociology, University of Sargodha, Sargodha, Pakistan
}

Dr.Babak Mahmood

Assistant Professor, Department of Sociology, University of Sargodha, Sargodha, Pakistan

Muhammad Asim

PhD Scholar, Department of Sociology, University of Sargodha, Sargodha, Pakistan

Malik Muhammad Sohail

Doi:10.5901/mjss.2015.v6n2s1p154

PhD Scholar, Department of Sociology, University of Sargodha, Sargodha, Pakistan

\section{Abstract}

The present study was aimed to explain the factors playing threatening role in creating the unhealthy life style and high risk Behaviour and to check the Behaviour of people towards health and illness Behaviour. The nature of the study was quantitative. A sample of 140 respondents was selected, from the district Sargodha, Punjab, Pakistan. Questionnaire was used as tool of data collection which contained questions Statistical package for social scientist (SPSS) was used to analyse. The result of the study showed that factors like gender, socioeconomic status, occupationand income effects health behaviour of the people. Majority agreed that lower class underutilized health services and upper class has high higher life expectancy while poor are poorer to stress due to financial costs. They also use rarely preventive care. In this study majority were agreed that rigid socialization of child can cause criminal Behaviour. Majority answered that unsanitary living conditions of the people can lead to unhealthy lifestyle. Majority were agreed that sickness is a social state created by the human perception and the sick person has the obligation to seek medical care and get well soon in case of any disease.

Keywords: Doctor-patient Interaction, Physician, Criminal Thoughts, Unhealthy behaviour

\section{Introduction}

Health Behaviour is an activity undertaken for the purpose of preventing or detecting disease or for improving health and well-being (Corner and Norman, 1996). Many previous studies examined the relationship between health Behaviour and health outcomes and their role in both morbidity and mortality (Blaxtar, 1990). Health Behaviours also impact on individuals' quality of life by delaying the onset of chronic disease and extending active lifespan (USDHHS, 1990). Smoking, alcohol consumption, diet, gaps in primary care services and low screening uptake are all significant determinants of poor health and changing such Behaviours lead to improved health.

According to Rosen (1979), improved medical care is also going to hand in hand with changed social conditions leading to a better life.

Kessler et al. (1994) found in their research women have higher rates of mood and anxiety disorders, while men have more personality disorder, which consist largely of impaired personality traits. Glass and Fujimoto (1994); Mirowsky and Ross, (1989) described, women who are employee outside the home have less psychological distress than housewives but more distress than employed men. According to studies of Rosenfield (1992), women's employment can also be negative for their husband's mental health if the men make less money from their job or have to do more housework because of it.

Stress is defined as heightened mind-body reactions to stimuli inducing fear or anxiety in the individual. Stress typically starts with a situation that people find threatening or burdensome (Pearlin, 1989). Examples of stressful situation include divorce (Aseltine et al., 1993), unpleasant work conditions (Fenwick et al, 1994), widowhood (Umberson et al., 1992) and unemployment.

Deviance relates to all forms of rule breaking whether this involves such things as murder, theft, the breaking of formal social rules. Criminal Behaviour is a form of deviance that one is defined as the breaking of legal rules (Chris Lisvey, 2010). Terrie Moffitt (1994) suggested that,some neurophysiologist, which study the brain activities believe that 
inherited or acquired neurological and physical abnormalities control Behaviour throughout life span.

G.B. Ramirez and et al (2003) suggested that a healthful diet can provide minimal levels of minerals and chemicals needed for normal brain functioning and growth, especially in early tears of life. An improper diet can cause chemical and mineral imbalance and can lead to cognitive and learning deficits and problems, and these factors in turn are associated with antisocial Behaviours. Eric Konofal et al. (2005) found that an over-or undersupply of certain chemicals and minerals including sodium, mercury, potassium, calcium, aminocide and iron can lead to depression, hyperactivity, cognitive problems, memory loss, or abnormal sexual activity.

Brigette Erwin and et al (2000) described that people who physically or sexually abuse, especially young males, are much more likely to smoke, drink, and take drugs than nonabuse youth. Chris Melde and et al (2009) showed in their studies as adults, there is evidence that crime victims themselves are more likely than non-victims to commit crimes. Fearing re-victimization, they may take drastic measures and arms themselves for self- protection.

Sheldon and Eleanor (1950) suggested, family relationships are considered a major determinant of Behaviour. According to Alexandar and Lloyd (2003) In fact parenting factors such as the ability to communicate and to provide proper discipline may play a critical role in determining whether people misbehave as children and even later as adults.

Objectives of the present study are; to find the relation between social factors and unhealthy lifestyle and high risk behaviour, to check the effect of criminal thoughts on high risk behaviour and unhealthy lifestyle, to assess life styles spread across social boundary and to evaluate the existing study the role of doctors.

\section{Research Methodology}

The researcher must choose a research methodology to determine whether the relationship specified in a problem statement actually exist or not. The population of the present research was all the people from every sector of the society of the District Sargodha.Sample is representation of large whole. The universe of this study was the Sargodha city with the use of stratified sampling.A sample of 140 respondents from the district Sargodha has been taken because this was judgmental study. In order to collect data first of all strata were made of respondents and then convenient sampling was used in such a way that data could be collect from the people of every walk of life, of every age, gender, occupation, literate or illiterate. In this study the researcher used Questionnaire as tool for data collection.For the statistical analysis the process of coding was made. The mathematical numbers to show different variables coded different responses.For the description of the basis characteristics of the sample simple percentage were concluded. The purpose is simplify Quantitative characteristics in to numeric from the percentage was calculated by using the following formula.Chi-squire was applied to find out the relationship between certain independent and dependent variables.

\section{Results and Interpretations}

Table 1:

\begin{tabular}{|c|c|c|}
\hline Socio-economic \& demographic characteristics of respondents & Frequency & Percentage \\
\hline Gender & Mode:2 & Range:1 \\
\hline Male & 66 & 47.1 \\
\hline Female & 74 & 52.9 \\
\hline Age of the respondents & Mode:2 & Range:4 \\
\hline $10-20$ years & 12 & 8.6 \\
\hline $20-30$ years & 90 & 64.3 \\
\hline $30-40$ years & 13 & 9.3 \\
\hline 40-50 years & 22 & 15.7 \\
\hline Above & 3 & 2.1 \\
\hline Education & Mode:4 & Range:4 \\
\hline Metric & 24 & 17.1 \\
\hline Intermediate & 13 & 9.3 \\
\hline Graduation & 31 & 22.1 \\
\hline Postgraduate & 62 & 44.3 \\
\hline Iliterate & 10 & 7.1 \\
\hline Residence & Mode:2 & Range:2 \\
\hline Rural & 47 & 33.6 \\
\hline Urban & 77 & 55.0 \\
\hline Town & 16 & 11.4 \\
\hline
\end{tabular}




\begin{tabular}{|c|c|c|}
\hline Marital status & Mode:2 & Range:1 \\
\hline Married & 45 & 32.1 \\
\hline Single & 95 & 67.9 \\
\hline Family structure of the respondents & Mode:2 & Range:3 \\
\hline Nuclear & 60 & 42.9 \\
\hline Joint & 75 & 53.6 \\
\hline Extended & 5 & 3.6 \\
\hline Family monthly income & Mode:5 & Range:4 \\
\hline Below 20000 & 33 & 23.6 \\
\hline 20000-30000 & 24 & 17.1 \\
\hline 30000-40000 & 24 & 17.1 \\
\hline $40000-50000$ & 14 & 10.0 \\
\hline $50000+$ & 45 & 32.1 \\
\hline Total & 140 & 100 \\
\hline
\end{tabular}

Table 1 is indicating the frequency and percentage distribution of the respondents according to their age. Table depicts that majority $64 \%$ of the respondents' age belonged to the category of $20-30$ years, $15 \%$ belonged to $40-50$ years, $9 \%$ fell into the group of $30-40$ years, $8 \%$ are belonged to $10-20$ years and $2 \%$ are belonged to age above 50 years. Mode that is 2 also shows that majority respondents lying on the $64 \%$ so majority respondent's age is 20-30. Range that is 4 also shows that $2 \%$ respondents deviating from the data. Elderly people are more likely to visit physicians than younger people and women between the ages of fifteen and forty-four visits more to doctors. The above table is indicating the frequency and percentage distribution of respondents according to their gender. The table revealed that $52 \%$ respondents were females in this research and $47 \%$ were males. The mode also shows that mostly people are lying in the second category. As far as the dispersion of the data is covered, range that is 1 explicitly shows that data is dispersed. So majority respondents are females in this research and minority is male. Females are more fit biologically at birth, less often exposed to danger and highly stressful occupations, are more sensitive to their bodily states, and possibly enhance their life expectancy through more usage of medical services and males typically exceed female death rated at all stages and for the leading causes of death such as heart diseases, cancer, cerebrovascular diseases, accidents and pneumonia (Cokerham, 1998).

The above table is indicating the frequency and percentage distribution of respondents according to their marital status. It showed that $67 \%$ respondents were single and $32 \%$ were married. The mode 2 also shows that mostly people are lying in the second category and range that is 1 shows that 32\% people are dispersing from the data.Data shows that majority 55\% respondents were from the rural area and 33\% were from urban. It is found that $44 \%$ respondents were postgraduate, $22 \%$ were graduation, $17 \%$ were metric. It is found that $53 \%$ respondents in this research were belong to joint family system, $42 \%$ were from nuclear family system and $3 \%$ were from extended family system.

Above table indicates the frequency and percentage distribution of respondents according to their income. It is found that $32 \%$ of the respondents' households' income was above $50000,23 \%$ of the respondents' household income was below 20000, 17\% respondents' household income was 20000-30000 and 17\% was 30000-40000, and minority respondents' income was 40000-50000. The mode 5 showing that majority people are lying in the fifth category and range 4 also shows that $10 \%$ people are deviating from the data. Income of the people shows their social status. Dutton (1986) found in her studies that low income patients in public health care system confronted a lack of preventive examination, high charges for services, long waiting times and relatively poor patient-physician relationship. In this study the majority $47 \%$ were students, $24 \%$ were Government employees.

\begin{tabular}{|c|c|c|c|c|c|c|c|}
\hline \multicolumn{8}{|l|}{ Doctor-Patient Interaction } \\
\hline I think: & S.A & $\bar{A}$ & $\mathbf{N}$ & D & S.D 1 & Mean & S.D \\
\hline Poor can't communicate properly with the doctor due to lack of confidence. & $\begin{array}{c}25 \\
17.9 \%\end{array}$ & $\begin{array}{c}77 \\
55.0 \%\end{array}$ & $\begin{array}{c}13 \\
9.3 \%\end{array}$ & $\begin{array}{c}18 \\
12.9 \%\end{array}$ & \begin{tabular}{c|}
7 \\
$5.0 \%$
\end{tabular} & 2.32 & 1.068 \\
\hline $\begin{array}{l}\text { Women usually hesitate to talk freely and openly with doctor due to social } \\
\text { barriers. }\end{array}$ & $\begin{array}{c}35 \\
25.0 \%\end{array}$ & $\begin{array}{c}73 \\
52.1 \%\end{array}$ & $\begin{array}{c}17 \\
12.1 \%\end{array}$ & $\begin{array}{c}13 \\
9.3 \%\end{array}$ & \begin{tabular}{|c|}
2 \\
$1.4 \%$
\end{tabular} & 2.10 & 0.931 \\
\hline Some people don't allow women to go to male doctors due to cultural barriers. & $\begin{array}{c}19 \\
13.6 \%\end{array}$ & \begin{tabular}{|c|}
77 \\
$55.7 \%$
\end{tabular} & $\begin{array}{c}19 \\
13.6 \%\end{array}$ & $\begin{array}{c}23 \\
16.4 \%\end{array}$ & \begin{tabular}{|c|}
1 \\
$.7 \%$ \\
\end{tabular} & 2.35 & .936 \\
\hline $\begin{array}{l}\text { Some people don't go to doctor because they believe doctors keep patients } \\
\text { waiting too long. }\end{array}$ & $\begin{array}{c}24 \\
17.1 \%\end{array}$ & $\begin{array}{c}55 \\
39.3 \%\end{array}$ & $\begin{array}{c}33 \\
23.6 \%\end{array}$ & $\begin{array}{c}24 \\
17.1 \%\end{array}$ & \begin{tabular}{|c|}
4 \\
$2.9 \%$
\end{tabular} & 2.49 & 1.056 \\
\hline People don't go to doctor when they feel they are getting better. & $\begin{array}{c}34 \\
24.3 \%\end{array}$ & $\begin{array}{c}71 \\
50.7 \%\end{array}$ & $\begin{array}{c}22 \\
15.7 \%\end{array}$ & $\begin{array}{c}10 \\
7.1 \%\end{array}$ & \begin{tabular}{|c|}
3 \\
$2.1 \%$
\end{tabular} & 2.12 & 0.932 \\
\hline
\end{tabular}


Interpretation of data indicating that $55 \%$ were agreed in this study that poor can't communicate properly with the doctor due to lack of confidence, $17 \%$ were strongly agreed, $12 \%$ were disagreed. The mean 2.32 showing that the mostly people are lying in the $2^{\text {nd }}$ category and standard deviation 1.068 also shows the dispersion of the data. Howard Waitzkin (1991) suggested that social class differences are the most important factors in physician-patient communication. Sue Fisher (1984) identified, those patients who are similar to physicians in social class are more likely to share their communication style and communicate effectively with them.Majority $52 \%$ respondents were agreed that women hesitate to talk with doctor, $25 \%$ were strongly agreed, the mean 2.10 showing that majority respondents are lying in the $2^{\text {nd }}$ category and standard deviation also shows the dispersion of the data. Atkinson (1995); Ross and Duff (1982) found in their studies that two groups in society, the lower class and women, have been identified as having the most communication problems with physicians.

Majority respondents were agreed that some people don't go to doctor because they believe doctors keep patients waiting too long, $23 \%$ were neutral, $17 \%$ respondents were strongly agreed. The arithmetic mean 2.49 also shows that majority people are lying in the $2^{\text {nd }}$ category and standard deviation 1.056 also shows the dispersion of the data covered. $50 \%$ respondents were agreed that people don't go to doctor when they feel they are getting better, $24 \%$ were strongly agreed, $15 \%$ were neutral, and $7 \%$ were disagreed and minority $2 \%$ were strongly disagreed. The mean 2.12 showing that mostly people are lying in the $2^{\text {nd }}$ category and standard deviation 0.932 shows the dispersion covered from the data. Thompson (1984) suggested that physicians prescribe medications, diets and the like and expect patients to follow them faithfully.

\begin{tabular}{|c|c|c|c|c|c|c|c|}
\hline \multicolumn{8}{|l|}{ Physicians } \\
\hline Ithink: & S.A & A & $\mathbf{N}$ & D & S.D & Mean & S.D \\
\hline Physicians should ethically train. & \begin{tabular}{|c|}
59 \\
$42.1 \%$
\end{tabular} & $\begin{array}{c}66 \\
47.1 \%\end{array}$ & $\begin{array}{c}11 \\
7.9 \%\end{array}$ & $\begin{array}{c}1 \\
.7 \%\end{array}$ & $\mid \begin{array}{c}3 \\
2.1 \%\end{array}$ & 1.74 & 0.810 \\
\hline Doctors are mostly from upper and upper-middle class. & \begin{tabular}{|c|}
26 \\
$18.6 \%$
\end{tabular} & $\begin{array}{c}58 \\
41.4 \% \\
\end{array}$ & $\begin{array}{c}31 \\
22.1 \% \\
\end{array}$ & $\begin{array}{c}24 \\
17.1 \%\end{array}$ & \begin{tabular}{c|}
1 \\
$.7 \%$ \\
\end{tabular} & 2.40 & 1.002 \\
\hline Doctors should treat poor and rich equally. & \begin{tabular}{|c|}
62 \\
$44.3 \%$
\end{tabular} & \begin{tabular}{|c|}
43 \\
$30.7 \%$
\end{tabular} & $\begin{array}{c}20 \\
14.3 \%\end{array}$ & $\begin{array}{c}11 \\
7.9 \%\end{array}$ & $\begin{array}{c}4 \\
2.9 \%\end{array}$ & 1.94 & 1.078 \\
\hline Family, close relatives and family friends encourage in choosing medical prof & $\begin{array}{c}27 \\
19.3 \% \\
\end{array}$ & $\begin{array}{c}83 \\
59.3 \% \\
\end{array}$ & $\begin{array}{c}19 \\
13.6 \% \\
\end{array}$ & $\begin{array}{c}9 \\
6.4 \%\end{array}$ & \begin{tabular}{|c|}
2 \\
$1.4 \%$ \\
\end{tabular} & 2.11 & .840 \\
\hline Doctors should have an ambition to help people rather than to $m$ & $\begin{array}{c}61 \\
43.6 \%\end{array}$ & $\begin{array}{c}40 \\
28.6 \% \\
\end{array}$ & $\begin{array}{c}25 \\
17.9 \% \\
\end{array}$ & $\begin{array}{c}10 \\
7.1 \%\end{array}$ & \begin{tabular}{|c|}
4 \\
$2.9 \%$
\end{tabular} & 1.97 & 1.079 \\
\hline
\end{tabular}

The Interpretation of the dataregarding to the physicians should ethically train. The interpretation showing that majority $47 \%$ respondents in this study were agreed that doctors should be ethically trained, $42 \%$ were strongly agreed, $7 \%$ were neutral, $2 \%$ were strongly disagreed and minority .7\% were disagreed. The mean 1.74 showing that mostly people are lying in the $2^{\text {nd }}$ category and standard deviation 0.810 also shows the dispersion of the data Quah (1989) suggested that physicians generally control the conditions of their own work and the work of most of the other members of the health professionals as well. Physicians should have ethically trained to deal effectively with the patients.

$41 \%$ respondents were agreed that doctors are mostly from upper and upper-middle class, $18 \%$ were strongly agreed and $22 \%$ were neutral. An equitable majority respondent said that doctors should treat poor and rich equally. Interpretation of dataregarding family as motivating factor in choosing medical profession manifests those majority respondents reported that family, close relatives and family friends encourage in choosing medical profession. The mean 2.11 showing that mostly people are lying in the $2^{\text {nd }}$ category as far as dispersion of the data is covered, the standard deviation .840 shows the dispersion of the data. majority $43 \%$ respondents were strongly agreed that doctors should have ambition to help people rather than to make money, $28 \%$ were agreed, $17 \%$ were neutral, and $7 \%$ were disagreed and minority $2 \%$ were strongly disagreed. The mean 1.97 showing that mostly people are lying in the $1^{\text {st }}$ category and standard deviation 1.079 shows the dispersion of the data. Becker et al (1961) suggested that, medicine is the best of all professions.

\begin{tabular}{|c|c|c|c|c|c|c|c|}
\hline \multicolumn{8}{|l|}{ Criminal Though } \\
\hline I think: & S.A & A & $\mathbf{N}$ & D & S.D & Mean & S.D \\
\hline $\begin{array}{l}\text { Improper diet can cause chemical and mineral imbalance and lead to criminal } \\
\text { behaviour. }\end{array}$ & $\begin{array}{c}17 \\
12.1 \%\end{array}$ & $\begin{array}{c}67 \\
47.9 \%\end{array}$ & $\begin{array}{c}23 \\
16.4 \%\end{array}$ & \begin{tabular}{|c|c|}
31 \\
$22.1 \%$
\end{tabular} & $\begin{array}{ll}2 \\
4 \%\end{array}$ & 2.53 & $\mid 1.014$ \\
\hline Some persons suffer from mental disorder cause criminal behaviour. & \begin{tabular}{|c|}
16 \\
$11.4 \%$
\end{tabular} & $\begin{array}{c}70 \\
50.0 \%\end{array}$ & $\begin{array}{c}38 \\
27.1 \%\end{array}$ & $\begin{array}{c}16 \\
11.4 \%\end{array}$ & 0 & 2.39 & $0.836 \mid$ \\
\hline Antisocial behaviour leads to criminal thoughts. & \begin{tabular}{|c|}
29 \\
$20.7 \%$
\end{tabular} & $\begin{array}{c}67 \\
47.9 \%\end{array}$ & $\begin{array}{c}30 \\
21.4 \%\end{array}$ & $\begin{array}{c}12 \\
8.6 \%\end{array}$ & \begin{tabular}{|c|}
2 \\
$1.4 \%$
\end{tabular} & 2.22 & 0.922 \\
\hline
\end{tabular}




\begin{tabular}{|l|c|c|c|c|c|c|c|}
\hline Rigid socialization of the child can cause criminal behaviour. & 20 & 79 & 25 & 12 & 4 & 2.29 & 0.917 \\
\hline Some people became criminal due to loss of their loved ones. & $14.3 \%$ & $56.4 \%$ & $17.9 \%$ & $8.6 \%$ & $2.9 \%$ & 2.29 & 25 \\
\hline Narrow minded people and their rigid thinking cause criminal behaviour. & 25 & 60 & 37 & 16 & 2 & 2.36 & 0.953 \\
\hline
\end{tabular}

A majority $47 \%$ respondent were agreed that improper diet can lead to criminal behaviour, $22 \%$ was disagreed while $16 \%$ were neutral. The mean 2.53 showing that mostly people are lying in the $2^{\text {nd }}$ category and standard deviation 1.014 shows the dispersion of the data. John Cloud (1999) also found in their research that biochemical condition including genetically and that are acquire from diet and environment influence antisocial behaviour.Majority $50 \%$ respondents were agreed that some person that suffers from mental illness can be criminal, $27 \%$ were neutral. Kevin Beaver and et al (2007), neurological impairment lead to the development of personality traits linked to antisocial behaviour.

A majority $47 \%$ was agreed that antisocial behaviour leads to criminal thoughts, $21 \%$ were neutral, $20 \%$ were strongly agreed. The mean 2.22 showing that mostly people are falling in the $2^{\text {nd }}$ category as far as dispersion of data is covered, the standard deviation 0.922 shows the dispersion of the data. People who are crime victims may be more likely to commit crime themselves (Timothy and Cathy, 1995). The process may begin early in life, because being abused or neglected as a child increase the odds of being arrested, both as a juvenile and as an adult.

$56 \%$ study participants were agreed that rigid socialization of child can cause criminal behaviour, $17 \%$ were neutral while 14\% were strongly agreed.John and Francis (2001) Parents who are supportive and who effectively control their children in a non-coercive way are more likely to raise their children who refrain from delinquency. $42 \%$ respondents were agreed that some people become criminal due to loss of their loved ones. Eric and Shelly (2008) also found that such individuals may be impulsive and have difficulty concentrating and consequently experience difficulty in school. A majority $48 \%$ respondents were agreed that narrow minded people with rigid thinking lead to criminal behaviour, $26 \%$ was neutral, while $9 \%$ disagreed. The mean 2.35 showing that the majority respondents are lying in the $2^{\text {nd }}$ category and standard deviation 0.889 showing the dispersion of the data covered.

\begin{tabular}{|c|c|c|c|c|c|c|c|}
\hline \multicolumn{8}{|l|}{ Unhealthy lifestyle/High Risk Behaviour } \\
\hline I think: & S.A & A & $\mathbf{N}$ & D & S.D & Mean & S.D \\
\hline In case of any disease I go traditional Hakim. & $\begin{array}{c}14 \\
10.0 \%\end{array}$ & $\begin{array}{c}27 \\
19.3 \%\end{array}$ & $\begin{array}{c}27 \\
19.3 \%\end{array}$ & $\begin{array}{c}43 \\
30.7 \%\end{array}$ & $\begin{array}{c}29 \\
20.7 \%\end{array}$ & 3.33 & 1.278 \\
\hline go often to doctor for check up during disease. & $\begin{array}{c}24 \\
17.1 \%\end{array}$ & $\begin{array}{c}68 \\
48.6 \% \\
\end{array}$ & $\begin{array}{c}26 \\
18.6 \%\end{array}$ & $\begin{array}{c}22 \\
15.7 \%\end{array}$ & 0 & 2.33 & .940 \\
\hline I use medicines regularly and follow the recommendations of doctor. & $\begin{array}{c}20 \\
14.3 \%\end{array}$ & $\begin{array}{c}65 \\
46.4 \%\end{array}$ & $\begin{array}{c}27 \\
19.3 \%\end{array}$ & $\begin{array}{c}22 \\
15.7 \%\end{array}$ & $\begin{array}{c}6 \\
4.3 \%\end{array}$ & 2.49 & 1.056 \\
\hline I use proper diet and take regular exercise to maintain your health. & $\begin{array}{c}17 \\
12.1 \% \\
\end{array}$ & $\begin{array}{c}67 \\
47.9 \% \\
\end{array}$ & $\begin{array}{c}45 \\
32.1 \% \\
\end{array}$ & $\begin{array}{c}11 \\
7.9 \% \\
\end{array}$ & 0 & 2.36 & .796 \\
\hline Poor use rarely preventive care. & $\begin{array}{c}11 \\
7.9 \%\end{array}$ & $\begin{array}{c}85 \\
60.7 \%\end{array}$ & $\begin{array}{c}25 \\
17.9 \%\end{array}$ & $\begin{array}{c}16 \\
11.4 \%\end{array}$ & \begin{tabular}{|c|}
3 \\
$2.1 \%$
\end{tabular} & 2.391 & .871 \\
\hline Media motivates people towards healthy lifestyle. & \begin{tabular}{|c|c}
29 \\
$20.7 \%$ \\
\end{tabular} & \begin{tabular}{|c|}
70 \\
$50.0 \%$ \\
\end{tabular} & $\begin{array}{c}22 \\
15.7 \% \\
\end{array}$ & $\begin{array}{c}15 \\
10.7 \%\end{array}$ & \begin{tabular}{|c|c|}
4 \\
$2.9 \%$ \\
\end{tabular} & 2.25 & .997 \\
\hline Unsanitary living conditions of the people can lead to unhealthy lifestyle. & $\begin{array}{c}41 \\
29.3 \%\end{array}$ & $\begin{array}{c}72 \\
51.4 \%\end{array}$ & $\begin{array}{c}21 \\
15.0 \%\end{array}$ & \begin{tabular}{|c|c}
5 \\
$3.6 \%$
\end{tabular} & $\begin{array}{c}1 \\
.7 \%\end{array}$ & 1.950 & .808 \\
\hline Too much cigarette smoking and alcohol usage can cause many lungs diseases. & $\begin{array}{c}64 \\
45.7 \%\end{array}$ & $\begin{array}{c}55 \\
39.3 \% \\
\end{array}$ & $\begin{array}{c}13 \\
9.3 \% \\
\end{array}$ & $\begin{array}{c}6 \\
4.3 \% \\
\end{array}$ & \begin{tabular}{|c|}
2 \\
$1.4 \%$ \\
\end{tabular} & 1.76 & .895 \\
\hline Clean and pure water can prevent us from many diseases. & $\begin{array}{c}56 \\
40.0 \% \\
\end{array}$ & $\begin{array}{c}61 \\
43.6 \% \\
\end{array}$ & $\begin{array}{c}21 \\
15.0 \% \\
\end{array}$ & $\begin{array}{c}2 \\
1.4 \% \\
\end{array}$ & 0 & 1.79 & .80 \\
\hline Exposure to environmental pollution is a big factor of ill health in modern societies. & $\begin{array}{c}60 \\
42.9 \% \\
\end{array}$ & $\begin{array}{c}68 \\
48.6 \% \\
\end{array}$ & \begin{tabular}{|c|}
8 \\
$5.7 \%$ \\
\end{tabular} & $\begin{array}{c}2 \\
1.4 \% \\
\end{array}$ & \begin{tabular}{|c|}
2 \\
$1.4 \%$ \\
\end{tabular} & 1.70 & .765 \\
\hline $\begin{array}{l}\text { People by changing their behaviour by taking proper diet, exercise and better } \\
\text { living conditions can minimize their chance of becoming sick. }\end{array}$ & $\begin{array}{c}54 \\
38.6 \%\end{array}$ & $\begin{array}{c}62 \\
44.3 \% \\
4\end{array}$ & $\begin{array}{c}20 \\
14.3 \%\end{array}$ & 0 & \begin{tabular}{|c|}
4 \\
$2.9 \%$ \\
\end{tabular} & 1.84 & .875 \\
\hline
\end{tabular}

The Interpretation of the data indicating that majority $30 \%$ respondents said that they don't go to Hakim in case of any disease, $20 \%$ were strongly disagreed about this, 19\% were agreed and 19\% were strongly agreed. The mean 3.33 showing that mostly people are lying in the $4^{\text {th }}$ category and standard deviation 1.278 shows the dispersion of the data. Majority $48 \%$ respondents were agreed that they go to doctor for check-up during in any disease and minority $15 \%$ were 
disagreed. The mean 2.33 showing that majority respondents are lying in the $2^{\text {nd }}$ category and standard deviation .940 shows the dispersion covered from the data. A majority $46 \%$ respondent were agreed that they use medicines and follow the recommendations of doctor during any disease. Improved medical care is also going to hand in hand with changed social conditions leading to a better life (Rosen, 1979). Majority 47\% respondents were agreed that they use proper diet ant take regular exercise to maintain health, $32 \%$ were agreed. The mean 2.36 showing that majority respondents are lying in the $2^{\text {nd }}$ category as far as dispersion of the data is covered, the standard deviation .796 shows the dispersion of the data. $60 \%$ respondents were agreed that poor use rarely preventive care. The mean 2.391 showing that majority people are lying in the $2^{\text {nd }}$ category and standard deviation .871 shows the dispersion covered from the data.

$50 \%$ respondents were agreed that media motivates people towards healthy lifestyle, $20 \%$ were strongly agreed. A majority $51 \%$ respondent were agreed that Unsanitary living conditions of the people can lead to unhealthy lifestyle and $29 \%$ were strongly agreed. The mean 1.950 showing that majority people are lying in the $2^{\text {nd }}$ category as far as dispersion is covered from the data, the standard deviation .808 shows the dispersion of the data. $45 \%$ respondents were strongly agreed that too much cigarette smoking and alcohol usage can cause lung diseases and $39 \%$ were agreed. The mean 1.76 showing that majority respondents are lying in the $1^{\text {st }}$ category and standard deviation .895 shows the dispersion of the data. $43 \%$ respondents were agreed that clean and pure water can prevent us from many diseases and $40 \%$ were strongly agreed. $48 \%$ respondents were agreed that exposure to environmental pollution is a big factor of ill health while $42 \%$ were strongly agreed. The mean 1.70 showing that mostly people are falling in the $2^{\text {nd }}$ category and standard deviation .765 showing the dispersion covered from the data. Majority $44 \%$ respondents in this study were agreed that people can minimize their chance of becoming sick by changing their behaviour, 38\% were strongly agreed. The mean 1.84 showing that majority people are lying in the $2^{\text {nd }}$ category and standard deviation .875 shows the dispersion of the data.

\section{Bi-Variate Analysis}

Hypothesis No.4: There is strong association between Doctor-Patient interaction and Unhealthy lifestyle/high risk Behaviour

\begin{tabular}{|l|c|c|c|c|}
\hline Statements & Chi Square value & d.f & P-value & Gamma Value \\
\hline Doctor patient interaction & 2.059 & 4 & .725 & -.057 \\
\hline Criminal thought & 22.456 & 4 & .000 & .392 \\
\hline
\end{tabular}

The Doctor-patient interaction decreasing by decreasing high risk Behaviour on the other hand high risk Behaviour is increasing by decreasing doctor-patient interaction. So it is concluded that there is high very low association between doctor-patient interaction and high risk Behaviour because p-value is .725 and Gamma value -.057 also showed negative relationship between two variables doctor-patient interaction and high risk Behaviour, it means that doctor-patient interaction had negative impact on high risk Behaviour. So the hypothesis "there is strong association between doctorpatient interaction and unhealthy lifestyle/high risk Behaviour" is rejected. Cokerham (1998) found in his studies that the physicians has the dominant role since he or she is the one invested with medical knowledge and expertise, while the patient holds a subordinate position oriented toward accepting, rejecting, or negotiating the recommendation for treatment being offered. Patients cooperate with doctors and doctors attempt to return patient as normal a level of functioning as possible. When people visit doctors for treatment and medical advice, doctors usually (but not always) take some action to satisfy the patient's expectations.

The criminal thought has been decreased by increasing high risk Behaviour on the other hand high risk Behaviour has been increased by decreasing criminal thoughts. So it can be concluded that there is highly significant relationship between these two variables because p-value is .000 and Gamma value .392 also showed positive relationship. Therefore the hypothesis "There is positive association between criminal thought and high risk Behaviour" is accepted. According to Chris Lisvey (2010),deviance, the concept relate to of all forms of rule- breaking whether this involves such things as murder, theft, the breaking of formal social rules or such things as wearing inappropriate clothing for a given social situation, failing to produce homework at school or being cheeky to a parent- teacher and so forth -more-or-less the breaking of relatively informal social rules. Criminal Behaviour is a form of deviance that one is defined as the breaking of legal rules. 


\section{Conclusion}

In this research it has been investigated that how social factors play role in creating unhealthy lifestyle and high risk Behaviour of the people. The results of our findings gave us a lot of experience about health Behaviour, illness Behaviour, and doctor-patient interaction. It is concluded from this research that rising cost and demands of resources are common almost everywhere mostly in the lower class. The lower class has more prone to unhealthy lifestyle and high risk Behaviour. Modern medical care may be an unaffordable luxury, it is concentrated in urban areas and rural residents are left to cope with illness on their own or seek out traditional healers.

\section{References}

AlexandarVazsonyi and Lloyd Pickering ((2003), "The importance of family and school Domains in Adolescents Deviance". The African American and Caucasian Youth and adolescence .

Alder, N and Metthews, K, (1994). Health psychology: why do some people get sick and some stay well? Annual review of psychology 45:229-258.

Asletin, Robert H., JR., Ronald C. Kessler. (1993). "Marital Disruption and depression in a community sample". Journal of Health and Social Behavior, 34:237-251.

Blaxtar, M (1990). Helath and Lifestyle: London, Routledge.

Brigette Erwin, Elana Newman, Robert McMackin, Carlo Morrissey and Danny Kalaoupek (2000). "PTSD Maladjustment Environment and Criminality among Criminally involved Male Adolescents". Criminal Justice and Behavior 27:196-215.

Chris Lisvey. (2010). Sociology central Teaching Notes.Crime and Deviance Basic Concepts.www.sociology.org.uk.

Chris Melde, Finn-AageEsbensen and Terrance Taylor (2009). "May Peace Be With You: A Typological Examination of the Fear and Victimization Hypothesis of Adolescents weapon Carrying". Justice Quarterly 26:348-376.

Corner, M and Norman, P (1996) (eds.). Predicting Health Behavior. Buckingham, UK: Open University Press.

Eric Konofal, SamueleCortese, Michel Lecendreux, IsbabellArnulf and Marie Christine Mouren (2005)."Effectiveness of Iron Supplementation in a Young Child with Attention-Defficit/Hyperactivity Didorder".Pediatrics 116:732-734.

Fenwick, Rudy and Mark Tausig.(1994). "The macroeconomic context of job stress". Journal of Health and Social Behavior, 35:266-282.

G.B. Ramirez, O.Pagulayan, H. Akagi, A. Francisco Rivera, L. V Lee, A. Berroya, M.C. Vince Cruz and D. Casintahan (2003)." Tagum study II: Follow-up study at two years of age after parental exposure to Mercury". Pediatrics 111:298-195.

Glass Jennifer, and Testsushi Fujimoto. (1994). "Housework, paid work, and depression among husbands and wives." Journal of Health and Social Behavior, 35:179-191.

Kessler, Ronald C., Katherine A. McGonagle, Shaynang Zhao, Christopher B. Nelson, Michael Hughes, Suzann Eshleman, Hans-Ulrich Wittchen, and Kenneth S. kindler. (1994). "Lifetime and 12-month prevelance of DSM-III-R psychiatric disorders in the United States". Archives of General Psychiatry, 51:8-19.

Mirowsky, John, and Catherine E. Ross (1989).Social Causes of Psychlogical distress. New York: Aldine de Gruyter.

Pearlin, Leonard I. (1989). “The sociological study of stress". Journal of Health and Social Behavior, 30:241-256.

Rosen George. (1979). "The evolution of Social medicine. Pp.23-50 In handbook of medical Sociology, $2^{\text {nd }}$ ed., H. Freeman, S. Levine, and L. Reeder (eds). Englewood Cliffs, N.J.: Prentice Hall.

Rosenfield, Sarah (1992). "The costs of Sharing: Wives' employment: personal control and sex differences in mental health". Journal of Health and Social Behavior, 33:213-225.

Sheldon Glueck and Eleanor (1950), Unravelingjuveline Delinquency, Cambridge, M.A Harvard University Press.

Terrie Moffitt, Donald Lynam and Phil Sllva (1994)." Neuropsychological Tests Predicting Persistent Male Delinquency", Criminology 32:277-300.

US Department of Health and Services (1990) Health people 2000: National health promotion and Disease prevention Objectives. US department of health and human services, public health services, Washington, DC.

Umberson, Debra, Camille B. Wortman and Ronald C. Kessler. 1992. "Widowhood and depression: Explaining long-term gender differences in vulnerability". Journal of Health and Social Behavior, 30:131-146. 